\title{
Anabases
}

ANABASES Traditions et réceptions de l'Antiquité

5 | 2007

Varia

\section{Histoire des religions : pour faire une fin}

Jean-Marie Pailler

\section{OpenEdition}

Journals

Édition électronique

URL : http://journals.openedition.org/anabases/3213

DOI : 10.4000/anabases.3213

ISSN : 2256-9421

\section{Éditeur}

E.R.A.S.M.E.

Édition imprimée

Date de publication : 1 mars 2007

Pagination : 225-226

ISSN : 1774-4296

\section{Référence électronique}

Jean-Marie Pailler, «Histoire des religions : pour faire une fin », Anabases [En ligne], 5 | 2007, mis en ligne le 01 janvier 2012, consulté le 22 octobre 2019. URL : http://journals.openedition.org/anabases/ 3213 ; DOI : 10.4000/anabases.3213 
Anabases 5 (2007), p. 225-226

\section{Histoire des religions : pour faire une fin}

JeAn-Marie Pailler

$\mathrm{I}_{\mathrm{L}}$

L N'EST PAS OPPORTUN, je crois, de prolonger indéfiniment une discussion en partie engagée sur des malentendus. J'ai pris bonne note de la réplique de Philippe Borgeaud à mon article "Enseigner l'histoire des religions". Je rappelle ce titre, car il implique que je n'entendais nullement faire un compte rendu de son ouvrage, riche de bien des indications et suggestions dont on pourrait discuter ailleurs. Mon seul problème - mon seul "sujet d'irritation ", comme écrit Ph. B. - est le décalage qui risque de s'instaurer entre une vue extrêmement érudite de religions anciennes considérées préférentiellement sous l'angle des montages et démontages rituels ou mythiques, d'une part, et d'autre part la situation culturelle et didactique dans laquelle se trouvent des éducateurs ou conférenciers ayant à rendre compte, pour des publics divers mais bien éloignés de "la science des savants ", de données et enjeux devenus majeurs de l'histoire des religions.

Ce n'est donc pas par « christianocentrisme » $(\mathrm{Ph}$. B.) que j’ai rappelé ce qui me paraît être de l'ordre de la vérité d'évidence. C'est parce que nos jeunes et moins jeunes auditeurs, qu'ils soient musulmans, juifs, chrétiens ou agnostiques, attendent que nous leur livrions quelques clefs d'ordre évolutif et comparatif pour comprendre où nous en sommes et où ils en sont. De ce point de vue, il est évident que le regard des spécialistes des polythéismes - ce qui est un peu ma paroisse - doit accepter de se décentrer afin de situer l'émergence des " Religions du Livre " (que l'on me pardonne les majuscules) sur l'arrière-plan si complexe du " paganisme " des cités et des empires antiques. Le tout sans pédantisme, mais avec un respect des démarches spirituelles qui s'accommode mal d'une définition du religieux comme " offre de supermarché ".

Je vois mal comment mener à bien ce programme sans assumer quelques approximations contrôlées : ne pas avoir peur de parler, tout simplement, de "religion(s) ", ne pas dissocier à l'excès le " faire " (rituel) et le " croire " (mystique ou dogmatique), faire preuve du maximum de tolérance et d'ouverture compatible avec le refus des fondamentalismes, qu'ils soient religieuxfanatiques ou laïco-sectaires. De ce point de vue, je tiens à le redire, il serait dommageable d'interdire " intellectuellement " à un croyant de pratiquer l'histoire des religions, à un athée de "se 
faire une âme religieuse » pour comprendre son objet, et à un historien des religions de prendre son bien là où il le trouve, même si c'est, à l'occasion, chez Mircea Eliade ou chez René Girard. Le seul slogan qui vaille en la matière me paraît être : "Ni dieu, ni maître, ni gardien du temple ».

Jean-Marie PAILLER

Université de Toulouse II-Le Mirail

UFR d'Histoire, Arts et Archéologie

5, allées Antonio Machado

31058 Toulouse Cedex 9

pailler@univ-tlse2.fr 